\title{
Efficient Expression of Modified Human Papillomavirus 16 E6/E7 Fusion Protein and the Antitumor Efficacy in a Mouse Model
}

\author{
Xiaoshan Zhou, Xinlai Qian, Qingzheng Zhaо, ${ }^{*}$ Yuanzhi Lu, and Maolin XIONG \\ Cancer Institute, Peking Union Medical College and Chinese Academy of Medical Science; P. O. Box: 2258 Beijing \\ 100021 P. R. China. $\quad$ Received September 4, 2003; accepted November 28, 2003
}

\begin{abstract}
Infection with human papillomavirus, particularly type 16 (HPV16), is highly associated with the development of cervical intraepithelial neoplasia and cervical cancer. The two early viral oncogenes, E6 and E7, are selectively retained and constitutively expressed in tumor cells and are therefore attractive immunotherapeutic targets. Thus a vaccine strategy based on recombinant HPV16 E6/E7 fusion protein represents an efficient approach against HPV16-associated tumors. Although the expression level of HPV16 E6/E7 fusion protein was presumed to be low, direct experimental proof in vivo was lacking. To enhance the expression level and investigate its antitumor efficacy in vivo, we constructed a modified HPV16 E6/E7 fusion gene with three point-mutations and expressed it in Escherichia coli. The encoded protein, denoted $\mathrm{mE6} 6_{1-120} / \mathrm{mE}_{1-60}$, comprises $120 \mathrm{~N}$-terminus amino acids of E6 and $60 \mathrm{~N}$-terminus amino acids of E7 plus a histine tag, was purified on an affinity column, and subsequently characterized by Western blotting. Immunization of mice with $\mathrm{mE} 6_{1-120} / \mathrm{mE} 7_{1-60}$ completely protected them against subsequent challenge and rechallenge with TC-1 tumor cells expressing HPV16 E6 and E7 proteins. In the therapeutic experiments, most mice eliminated the preexisting tumors and had a long-term protection. Consistent with the results of in vivo experiments, the splenocytes from immunized mice elicited cytotoxic $T$ lymphocytes and specifically lysed TC-1 cells in vitro. More importantly, the expression level of $\mathrm{mE6}_{1-120} / \mathrm{mE}_{1-60}$ was significantly improved, meeting the necessary quantity required for a vaccine clinical trial. In conclusion, these data provide a scientific basis for the use of modified $\mathbf{m E 6}_{1-120} / \mathrm{mE}_{1-60}$ in future human trials.
\end{abstract}

Key words human papillomavirus 16 (HPV16); cervical cancer; immunotherapy; vaccine

Modern research has identified infection with human papillomavirus (HPV) as a major risk factor for the development of cervical neoplasia and cervical cancer. ${ }^{1)}$ More than $90 \%$ of cervical cancers contain HPV DNA, with type 16 being the most prevalent. ${ }^{2)}$ In most cases, the early viral E6 and E7 genes of high-risk HPV are integrated into the human genome and constitutively expressed in cervical cancer and cervical intraepithelial neoplasia (CIN). In addition, the two oncoproteins play a key role in the induction and maintenance of the transformation phenotype. ${ }^{3,4)}$ Therefore they are tumor-specific antigens and serve as ideal targets for the development of immunotherapy to prevent and treat HPV-16 associated CIN and cervical cancer. ${ }^{5)}$ Specific cell-mediated immune responses are believed to be critical for the elimination of HPV-infected cells or HPV-transformed cells. This assumption is based on the observations that in the majority of individuals HPV-induced lesions regress spontaneously, and that immunodeficient patients, like AIDS patients, develop significantly more HPV-associated lesions in the skin and anogenital tissue than immunocompetent individuals. ${ }^{6,7}$ E7and/or E6-specific cytotoxic T lymphocytes (CTLs) have been identified in patients with HPV $16^{+}$cervical cancers. ${ }^{89}$ Moreover, various studies in animal models indicated that it is possible to induce protection against HPV-containing tumors or to generate E6/E7-specific CTLs. ${ }^{10-17)}$ To augment CTL responses, various types of vaccines have been developed, such as E7 linked to heat-shock proteins or intracellular sorting molecules, ${ }^{18-20)}$ peptide/protein loaded on dendritic cells (DCs), ${ }^{13)}$ DNA, or RNA-transfected DCs. ${ }^{21)}$

Protein-based immunization is a simple, safe, and effective approach in vaccination against infectious and malignant diseases. Immunization with purified $\mathrm{E} 7$ protein or $\mathrm{L} 1 \Delta \mathrm{E} 7$ could yield efficient protection against tumor cells. ${ }^{13,14,22)}$ However, the E6-specific T cell immune response also plays a pivotal role in protection against persistent HPV infection and associated development of malignancies. Human CTL epitopes for the most frequent HLA-A molecules derived from E6 have been identified, most of which are located in the N-terminus. ${ }^{23)}$ In addition, E6-specific CTLs have been detected in cervical cancer patients. ${ }^{24)}$ Therefore a single protein comprising HPV16 E6 and E7 might elicit more potent immune responses. It has been demonstrated that the recombinant E6/E7 fusion protein could be engulfed by DCs in vitro, then undergo intracellular processing in the class I pathway, making the peptide fragments available for CTL recognition. ${ }^{25)}$ However, to the best of our knowledge, the expression level of the recombinant HPV16 E6/E7 fusion protein is very low ( $2.5 \%$ of total host protein), which limits its further application, and its antitumor efficacy in vivo has not yet been tested.

To improve the immunogenicity of HPV16 E6/E7 and investigate the antitumor efficacy in vivo, we modified the E6/E7 fusion gene. The newly designed gene encodes a fusion protein, comprising $120 \mathrm{~N}$-terminus amino acids of E6 and $60 \mathrm{~N}$-terminus amino acids of E7 plus 44 amino acids and a histine tag derived from vector. We also introduced three point-mutations into the fusion gene, resulting in three amino acid substitutions (E6 50 : Tyr-Gly; E7 24 : Cys-Gly; $\mathrm{E7}_{26}$ : Glu-Gly). Since some publications suggested that defined point-mutations in E7 not only eliminate its transformation potential, but significantly enhance its immunogenicity, ${ }^{26,27)}$ we expected that the introduced mutations might also enhance its immunogenicity. Our data showed that the $\mathrm{mE} 6_{1-120} / \mathrm{mE}_{1-60}$ expression level was significantly improved compared with that of $2.5 \%$ reported recently. ${ }^{25}$ The protein was specifically recognized by the E6 and E7 antibodies and elicited potent CTL responses in vitro. Immunization with $\mathrm{mE}_{1-120} / \mathrm{mE}_{1-60}$ effectively prevented and 
treated TC-1 tumors ${ }^{19,28)}$ in a mouse model. Together with other data, it could be concluded that this vaccine shows promise for clinical application in patients with HPV16-positive CIN or cervical cancer.

\section{MATERIALS AND METHODS}

Construction of the Recombinant Vector The $m E 6_{1-120}$ $\mathrm{mE}_{1-60}$ fusion gene containing three point-mutations (E6 E0 $_{\text {Tyr-Gly; E7 }}$ : Cys-Gly; E7 26 : Glu-Gly) was cloned into PUCm-T vector. The gene was polymerase chain reaction (PCR)-amplified from the PUCm-T vector. Primer sequences for the $\mathrm{mE} 6_{1-120} / \mathrm{mE}_{1-60}$ PCR were as follows: $5^{\prime}-$ GAGGAATTCCACCCAAAGAGAACTGCA-3'; and 5'-TATCTCGAGTTACTTGCAACAAAAGGTTAC-3'. PCR was performed under the following conditions: $94{ }^{\circ} \mathrm{C}$ for $30 \mathrm{~s}$, $50{ }^{\circ} \mathrm{C}$ for $40 \mathrm{~s}$, and $72^{\circ} \mathrm{C}$ for $1 \mathrm{~min}$ for 30 cycles, and $72^{\circ} \mathrm{C}$ for $8 \mathrm{~min}$. The gene was ligated into expression plasmid PET30a. The recombinant construct was confirmed by sequence analysis. The $\mathrm{mE}_{1-120} / \mathrm{mE}_{1-60}$ consisted of $120 \mathrm{~N}$-terminal amino acids of E6 and 60 N-terminal amino acids of E7 plus 44 amino acids and a histine tag derived from vector.

Induction and Purification of the $\mathrm{mE6}_{1-120} / \mathrm{mE}_{1-60}$ Fusion Protein Expression of the gene was induced by the addition of $1 \mathrm{~mm}$ isopropyl-B-D-thiogalactopyranoside (IPTG). Bacteria were harvested and lysed by sonication in the presence of aprotinin $2 \mu \mathrm{g} / \mathrm{ml}$, leupeptin $2 \mu \mathrm{g} / \mathrm{ml}$, pepstatin $2 \mu \mathrm{g} / \mathrm{ml}$, and $2 \mathrm{~mm}$ phenylmethyl sulfonyl fluoride (PMSF). Lysate containing recombinant protein was centrifuged at $10000 \mathrm{~g}$ for $20 \mathrm{~min}$ at $4{ }^{\circ} \mathrm{C}$ to obtain supernatant (soluble protein) and pellet (inclusion body) fractions, and the samples from the supernatant and pellet were analyzed by SDS-PAGE. $\mathrm{mE}_{1-120} / \mathrm{mE}_{1-60}$ was prepared from inclusion bodies by solubilization in $6 \mathrm{M} \mathrm{Gu}-\mathrm{HCl}$ and loaded onto a cobalt-chelating Sepharose column. The purification was performed according to the recommendations in the kit (BD BioSciences Clotech). The eluted protein was refolded by dialysis against $1 \times \mathrm{PBS}$, and stored at $-70^{\circ} \mathrm{C}$. The purified protein was analyzed using SDS-PAGE on $10 \%$ gel. In addition, the protein was verified by Western blot analysis against the E7 and the E6 antibodies.

Cell Lines and Mice The TC-1 cell line, kindly provided by T.-C. Wu (Johns Hopkins Medical Institutions), was derived from primary epithelial cells of C57BL/6 mice cotransformed with HPV16 E6 and E7 and activated c-Ha-ras oncogene. The cells were grown in RPMI 1640 (Gibco-BRL) supplemented with $10 \%(\mathrm{v} / \mathrm{v})$ fetal calf serum $(\mathrm{FCS})$, penicillin/streptomycin $50 \mathrm{U} / \mathrm{ml}, 2 \mathrm{~nm}$ glutamine, $1 \mathrm{~mm}$ sodium pyruvate, $2 \mathrm{~mm}$ nonessential amino acids, and G418 $0.4 \mathrm{mg} / \mathrm{ml}$ at $37^{\circ} \mathrm{C}$ with $5 \% \mathrm{CO}_{2}$. On the day of tumor challenge, TC-1 cells were harvested by trypsinization and washed twice with $1 \times$ PBS. Lewis lung cancer cells were maintained in our laboratory. Female C57BL/6 mice (8-10 weeks old) were purchased from the Experimental Animal Institute of Peking Union Medical College. Mice were kept under constant temperature conditions and fed sterilized food and water.

Measurement of Cytolytic Activity against TC-1 Tumor Cells Mice were immunized subcutaneously and boosted once with $2 \mathrm{nM} \mathrm{mE} 6_{1-120} / \mathrm{mE}_{1-60}$ or E7 (maintained in our laboratory) plus Incomplete Freund's Adjuvant
(IFA), or PBS plus IFA in the scruff of the neck, and CTLs were determined $7 \mathrm{~d}$ after the last booster immunization. Spleen cells were isolated, and $2 \times 10^{7}$ splenocytes were cocultured with $2 \times 10^{7}$ mitomycin C-treated TC-1 cells in a total volume of $5 \mathrm{ml}$ of medium in six-well plates (NUNCLON). Concanavalin A (ConA) and interleukin (IL)-2 (PEPRO Tech ET LTD) were added at a final concentration of $50 \mu \mathrm{g} / \mathrm{ml}$ and $10 \mathrm{U} / \mathrm{ml}$, respectively. After $5 \mathrm{~d}$ of stimulation, the viable splenocytes were recovered and used as effector cells in a nonradioactive cytolytic analysis, ${ }^{29,30)}$ and the TC-1 cells were used as target cells. The optimal number of target cells was 10000 as determined in a primary experiment. Effector cells were added to 10000 target cells at a ratio of $1: 1,11: 1$, and $33: 1$ (tested in triplicate). After 4-h inoculation, supernatants were pooled and measured for the release of lactate dehydrogenase (LDH) using a Non-Radioactive Cytotoxicity Assay kit (Promega) according to the manufacturer's instructions. Specific lysis was calculated according to the formula:

$$
\begin{aligned}
& \text { cytotoxicity }(\%) \\
& =\frac{\text { experimental-effector spontaneous }- \text { target spontaneous }}{\text { target maximum }- \text { target spontaneous }}
\end{aligned}
$$

Tumor Protection and Therapy Assay For in vivo tumor prevention experiments, female C57BL/6 mice $(n=10)$ were immunized in the scruff of the neck with $2 \mathrm{nM}$ $\mathrm{mE6}_{1-120} / \mathrm{mE}_{1-60}$ s.c. or E7 plus IFA, PBS plus IFA, or PBS alone, and then boosted $14 \mathrm{~d}$ later. Ten days after the booster, mice were inoculated in the left flank with $6 \times 10^{4}$ TC- 1 cells s.c. suspended in $200 \mu \mathrm{l} 1 \times$ PBS, and observed for $30 \mathrm{~d}$, and the tumor-free mice were rechallenged with a larger dose of TC- 1 cells $\left(2 \times 10^{5}\right)$ in the right flank. For in vivo therapeutic experiments, mice were injected with TC-1 cells $6 \times 10^{4}$ suspended in $1 \times$ PBS $200 \mu \mathrm{l}$, and then immunized with fusion protein on days 3 and 14 after the inoculation of TC-1 cells. Tumors were monitored twice a week, and tumor diameters were measured in two orthogonal dimensions using Vernier calipers. To determine whether immunization with $\mathrm{mE}_{1-120} / \mathrm{mE} 7_{1-60}$ provided long-term protection, the tumor-free mice were rechallenged with a larger dose of TC- 1 cells $\left(2 \times 10^{5}\right)$. Tumor volumes were calculated according to: volume $=$ length $\times$ width $^{2} / 2$. $^{31}$ )

\section{RESULTS}

Construction and Expression of the $\mathrm{mE} 6_{1-120} / \mathrm{mE}_{1-60}$ Fusion Gene and Purification of the Recombinant Fusion Protein The recombinant construct was verified by sequence analysis. Interestingly, the expression level of $\mathrm{mE}_{1-120}$ $\mathrm{mE}_{1-60}$ was high (about $40 \%$ of the total proteins of $E$. coli), and the amount of the fusion protein in the culture broth reached a maximum $5 \mathrm{~h}$ after IPTG induction (Fig. 1). $\mathrm{mE} 6_{1-120} / \mathrm{mE}_{1-60}$ mainly existed in the inclusion body. The lysate of the bacteria was analyzed by Western blotting with both the anti-E6 and the anti-E7 antibody (Fig. 2). The purity of $\mathrm{mE}_{1-120} / \mathrm{mE}_{1-60}$ was assessed at $90 \%$ using Gelpro software, and the purified protein was exchanged into $1 \times$ PBS and stored at $-70^{\circ} \mathrm{C}$.

Generation of CTLs To determine whether mE6 $6_{1-120} /$ $\mathrm{mE}_{1-60}$ showed cytolytic activity against TC- 1 cells, female 


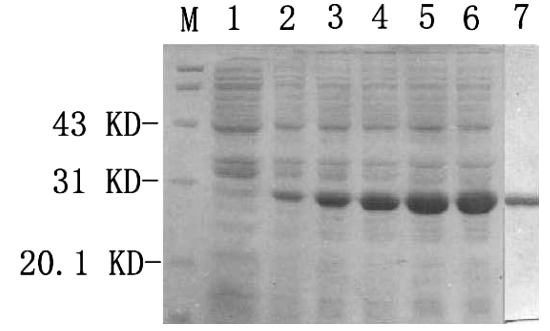

Fig. 1. SDS-PAGE Analysis of Fusion HPV mE6 ${ }_{1-120} / \mathrm{mE}_{1-60}$ Protein Expressed in E. coli.

$\mathrm{M}$, protein molecular weight marker; lane 1, total protein without IPTG induction; lanes $2-6$, total protein induced for $1,2,3,4$, and $5 \mathrm{~h}$; lane 7 , purified HPV16 $\mathrm{mE6}_{1-120} / \mathrm{mE}_{1-60}$ protein.

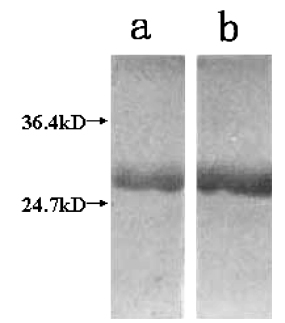

Fig. 2. Western-Blot Analysis of HPV16 $\mathrm{mE} 6_{1-120} / \mathrm{mE}_{1-60}$ Protein a, E6-antibody; b, E7-antibody.
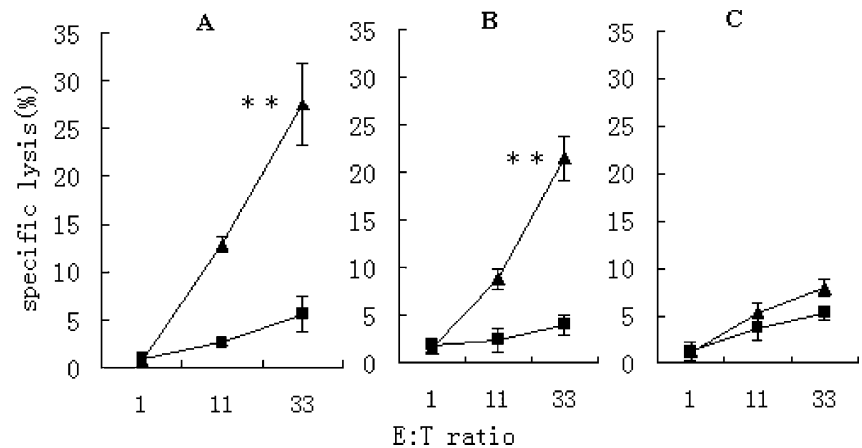

Fig. 3. Specific CTL Responses Induced by Immunization with $\mathrm{mE6}_{1-120} / \mathrm{mE}_{1-60}$ Plus IFA

C57BL/6 mice $(n=3)$ were injected with $2 \mathrm{nM} \mathrm{mE} 6_{1-120} / \mathrm{mE}_{1-60}$ plus IFA s.c. (A) or E7 protein plus IFA (B), or PBS plus IFA (C). Animals were boosted $7 \mathrm{~d}$ later. Seven days after the boost, pooled splenocyte cultures were prepared and restimulated for $5 \mathrm{~d}$ with mitomycin C-treated TC-1 cells and tested for cytolytic activity against the TC-1 cells $(\boldsymbol{\Delta})$ and Lewis lung carcinoma cells $(\boldsymbol{\square})$. Data are expressed as mean \pm S.E. of three separate experiments. $* * p<0.01$.

mice $(n=3)$ were immunized subcutaneously with mE6 $_{1-120} /$ $\mathrm{mE}_{1-60}$ or E7 plus IFA, or IFA plus PBS, and boosted $7 \mathrm{~d}$ later. Seven days after the last booster, pooled splenocyte cultures were prepared and restimulated in vitro with mitomycin C-treated TC-1 cells. Viable effector cells were assessed for cytotoxic activity against TC-1 cells or Lewis lung cancer cells, which were used as a negative control. As shown in Fig. 3, effector cells from $\mathrm{mE} 6_{1-120} / \mathrm{mE}_{1-60}$ and E7 proteinimmunized mice were more cytolytic than those from PBStreated mice for E6- and E7-expressing TC-1 target cells $(p<0.01)$. In addition, this cytolytic activity appeared specific for TC-1 cells, not Lewis lung cancer cells $(p<0.01)$.

Protection against Tumor Challenge and Rechallenge Given the ability of splenocytes from immunized mice to lyse TC-1 cells specifically, experiments were performed to determine whether immunization with $\mathrm{mE}_{1-120} / \mathrm{mE}_{1-60}$

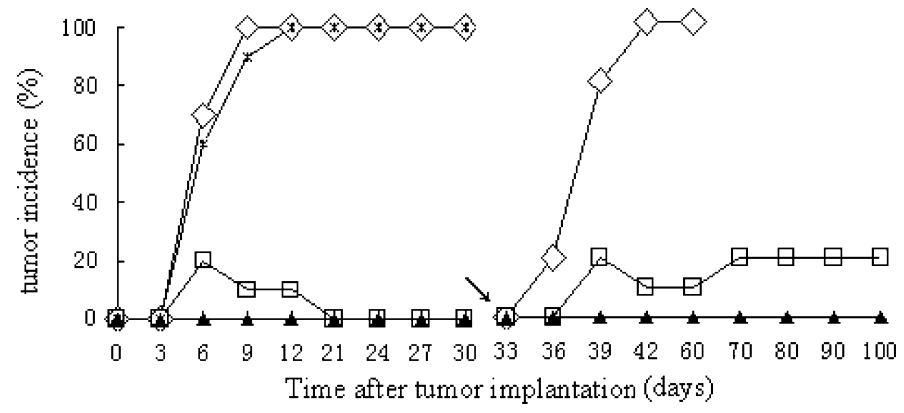

Fig. 4. Prophylactic Immunization with Recombinant $m E 6_{1-120} / \mathrm{mE} 7_{1-60}$ Protein against TC-1 Tumor Challenge and Rechallenge

C57BL/6 mice $(n=10)$ were immunized in the scruff of the neck with $2 \mathrm{~nm}$ $\mathrm{mE}_{1-120} / \mathrm{mE}_{1-60}$ plus IFA s.c. $(\boldsymbol{\Delta}), 2$ nM E7 plus IFA ( $\square$ ), PBS plus IFA (*), or PBS alone $(\diamond)$, and then boosted $14 \mathrm{~d}$ later. Ten days after the boost, mice were challenged in the left flank with $6 \times 10^{4} \mathrm{TC}-1$ cells s.c. (day 0 ) and observed for $33 \mathrm{~d}$. On day 33 (arrow), tumor-free mice were rechallenged with a larger dose of TC-1 cells $\left(2 \times 10^{5}\right)$ in the right flank and observed for an additional $67 \mathrm{~d}$. In addition, a new group of untreated mice $(\diamond)$ was challenged with tumor cells on day 33 to verify the tumorigenicity of the TC-1 inoculum. Mice that became moribund due to tumor burden were killed. Data are presented as percent tumor incidence per group.

could generate protective immunity against a subsequent tumor challenge. C57BL/6 mice $(n=10)$ were immunized and boosted with $\mathrm{mE} 6_{1-120} / \mathrm{mE}_{1-60}$ or E7 protein plus IFA, and challenged subcutaneously with TC-1 cells. As a negative control, the mice were injected PBS $(n=10)$ or PBS plus IFA $(n=10)$. The results demonstrated that all of the naive mice developed palpable tumors within $7-10 \mathrm{~d}$ after the inoculation of TC-1 cells. On day 30 , the mice in control groups became moribund due to tumor burden and were killed. By contrast, all mice vaccinated with $\mathrm{mE}_{1-120} /$ $\mathrm{mE7}_{1-60}$ remained tumor free for $33 \mathrm{~d}$. Two of 10 mice in the E7 group developed palpable tumors and declined within the next 3-6d. On day 33, the tumor-free mice were rechallenged with a larger dose of TC-1 cells. None of the mE6 $6_{1-120} /$ $\mathrm{mE}_{1-60}$ immunized mice developed tumors and remained tumor free by the end of the observation period. Tumors occurred in 2 of the E7-immunized mice (Fig. 4), but the difference between the $\mathrm{mE}_{1-120} / \mathrm{mE} 7_{1-60}$ and E7 group was not significant $(p=0.237)$. To verify the tumorigenicity of TC-1 cells, a new cohort of mice $(n=10)$ was used as a control group. As expected, all mice developed tumors within $6-10$ d.

Therapeutic Experiments Since the immunization of mice with the fusion protein protected them against TC-1 cell challenge and rechallenge, we further investigated whether vaccination with $\mathrm{mE}_{1-120} / \mathrm{mE}_{1-60}$ could lead to regression of preexisting tumors. In these studies, mice were injected with $6 \times 10^{4}$ cells s.c. on the left flank, and then on days 3 and 14 post inoculation were injected with $2 \mathrm{~nm}$ $\mathrm{mE}_{1-120} / \mathrm{mE}_{1-60}$ plus IFA, PBS plus IFA, or PBS alone. In the PBS plus IFA and PBS groups, $60 \%$ and $90 \%$ of mice developed tumors within 6-10 d after the inoculation of TC-1 cells, respectively. Only 2 ultimately developed tumors in the mE6 ${ }_{1-120} / \mathrm{mE}_{1-60}$-immunized group (Fig. 5), and thus the rate of tumor take was significantly lower than in those in the PBS plus IFA group $(p=0.01)$ or the PBS alone group $(p=0.03)$. Additionally, the growth rate in the $\mathrm{mE6}_{1-120} /$ $\mathrm{mE7}_{1-60}$ group was slower than that in the PBS plus IFA and PBS groups (data not shown). On day 33, the tumor-bearing mice that became moribund due to tumor burden were killed. 


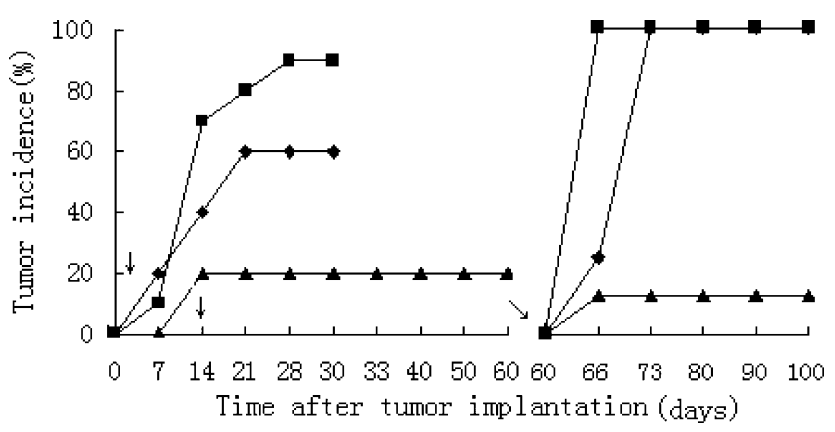

Fig. 5. Therapeutic Immunization with $\mathrm{mE} 6_{1-120} / \mathrm{mE} 7_{1-60}$ Induction Tumor Regression and Protection against Tumor Rechallenge

C57BL/6 mice $(n=10)$ were injected with $6 \times 10^{4} \mathrm{TC}-1$ cells s.c in the left flank (day 0 ). On days 3 (arrow) and 14 (arrows) postimplantation, the mice were immunized with $2 \mathrm{nM} \mathrm{mE6}_{1-10} / \mathrm{mE}_{1-60}$ plus IFA $(\boldsymbol{\Delta})$, PBS plus IFA $(\bullet)$, or PBS alone $(\boldsymbol{\square})$ in the scruff of neck. The presence of tumor was monitored for $60 \mathrm{~d}$. Mice that became moribund due to tumor burden were killed. On day 60 (diagonal arrow), the tumor-free mice from the above groups were rechallenged in the right flank with a larger dose of TC-1 cells $\left(2 \times 10^{5}\right)$ and observed for an additional $40 \mathrm{~d}$. Data are presented as percent tumor incidence per group.

Subsequently, the tumor-free mice from the above groups were used for rechallenge experiments and inoculated with a larger dose of TC- 1 cells $\left(2 \times 10^{5}\right)$. All tumor-free mice from the PBS or PBS plus IFA group developed palpable tumors within $4-6 \mathrm{~d}$. Seven of 8 mice immunized with $m E 6_{1-120} /$ $\mathrm{mE}_{1-60}$ protein remained tumor free over the next $40-\mathrm{d}$ observation period. This suggests that immunization of mice with $\mathrm{mE}_{1-120} / \mathrm{mE}_{1-60}$ plus IFA prevents outgrowth of TC1 cells and yields long-lasting protective immunity.

\section{DISCUSSION}

The two early viral E6 and E7 oncoproteins are tumor-specific antigens, since HPV virus can not be propagated in tissue culture to purified proteins for a vaccine and attenuated virus can not be used in vaccine due to its oncogenic potential. Therefore proteins used for vaccine are mainly recombinant proteins expressed by prokaryotic or eukaryotic systems. The HPV16 E6/E7 fusion protein represents a safe and efficient protein vaccine against HPV-associated tumors, although the expression level was reported to be only about $2.5 \%$ of the total protein of the host, ${ }^{23)}$ which markedly limits its further application. In our study, the expression level of $\mathrm{mE}_{1-120} / \mathrm{mE}_{1-60}$ was significantly improved, and the amount was about $40-50 \%$ of the total cell protein. Thus the amount of recombinant protein was significantly enhanced, and sufficient protein could be easily produced and purified in the quantity necessary for a clinical vaccine trial.

In this study, utilizing the E6- and E7-expressing murine tumor cell line TC-1 as a model of cervical carcinoma, we evaluated the antitumor efficacy of $\mathrm{mE} 6_{1-120} / \mathrm{mE}_{1-60}$. Cellmediated immune responses play an important role in antitumor responses. ${ }^{6,7)}$ It has been demonstrated that immunization with $\mathrm{E} 7$ or $\mathrm{L} 1 \Delta \mathrm{E} 7_{1-60}$ protein activates CTL responses and induces tumor protection in vivo. ${ }^{13,22)}$ In our study, immunization with $\mathrm{mE} 6_{1-120} / \mathrm{mE} 7_{1-60}$ also elicited specific CTLs, which was demonstrated by the fact that these CTLs specifically lysed target cells expressing E6 and E7, but not Lewis lung cancer cells. In the prophylactic experiments, vaccination with $\mathrm{mE}_{1-120} / \mathrm{mE}_{1-60}$ protected all the mice against TC-1 cell challenge and larger-dose rechallenge. We also compared the antitumor efficacy of $\mathrm{mE}_{1-120} / \mathrm{mE} 7_{1-60}$ with that of E7. During the first tumor challenge experiments, E7-vaccinated mice rejected the TC-1 cell challenge, as observed previously, ${ }^{13)}$ but 2 mice in the E7 group developed transient tumors, which immediately declined within the next $4-6 \mathrm{~d}$. When challenged again with a larger dose of tumor cells, 2 mice developed tumors during the observation period. However, all the mice in the $\mathrm{mE}_{1-120} / \mathrm{mE}_{1-60}$ group rejected the second, larger tumor cell challenge. This result demonstrated that $\mathrm{mE}_{1-120} / \mathrm{mE}_{1-60}$ might induce stronger antitumor immune responses than E7. The fusion protein comprises HPV16 E6 and E7, and all the possible epitopes in either E6 or E7 protein could be processed and presented by antigen-presenting cells and recognized by the host immune system. Thus the amount and variety of CTLs would increase, leading to a more effective antitumor response. It has been demonstrated that immunization of $\mathrm{BABL} / \mathrm{c}$ mice with recombinant adenovirus-E6 vaccine protects against HPV16-transformed tumor cell challenge. ${ }^{32)}$ In addition, immunization of rabbits with the E6 gene of cottontail rabbit papillomavirus provides partial protection against virus challenge. ${ }^{33)}$ Furthermore, it has been reported that in women with abnormal cervical cytology and biopsy-confirmed CIN, the responses to N-terminal HPV16 E6 peptide were associated with the clearance of HPV infection and the regression of $\mathrm{CIN}^{34)}$ Therefore $\mathrm{mE}_{1-120} / \mathrm{mE}_{1-60}$ holds promise for future clinical applications. The introduced mutation might also contribute to the enhanced immunogenicity of the fusion protein, since similar results have been reported by other investigators using DNA vaccine or modified peptide vaccine. ${ }^{26,27,35)}$ Consistent with the in vivo experiments, splenoctyes from both $\mathrm{mE} 6_{1-120} / \mathrm{mE}_{1-60^{-}}$and E7-immunized mice specifically recognized and lysed TC-1 cells in vitro. The level of CTL activity induced by E7 was low compared with that of $\mathrm{mE} 6_{1-120} / \mathrm{mE}_{1-60}$, although the difference was not significant $(p>0.05)$. In the therapeutic experiments, our data demonstrated that vaccination with $\mathrm{mE}_{1-120} /$ $\mathrm{mE} 7_{1-60}$ eliminated the preexisting tumors. In addition, to confirm the specificity of the protection conferred by $\mathrm{mE6}_{1-120} / \mathrm{mE}_{1-60}$, we challenged the $\mathrm{mE6}_{1-120} / \mathrm{mE}_{1-60^{-}}$ immunized mice with Lewis lung carcinoma cells. As expected, all mice developed tumors, and the splenoctyes from mE6 ${ }_{1-120} / \mathrm{mE}_{1-60}$-immunized mice could not lyse the Lewis lung carcinoma cells in vitro.

The fusion protein vaccine has several advantages over peptide and virus vaccines. First, $\mathrm{mE}_{1-120} / \mathrm{mE}_{1-60}$ could be engulfed, processed, and presented by antigen-presenting cells and recognized by different host immune systems. Thus no patients would be excluded because of epitope restrictions. When peptides are used as vaccines, the patient's HLA haplotype must be identified to choose peptides compatible with that particular haplotype, which considerably limits their usage, especially in developing countries. Second, this approach avoids the potential oncogenic risk of viral vectors as well as the E6 and E7 oncogenes. Finally, T helper cell responses might be simultaneously induced.

In summary, we significantly improved the expression level of $\mathrm{mE}_{1-120} / \mathrm{mE}_{1-60}$ of HPV 16 , and immunization with the purified protein had a specific and long-lasting prophylactic and therapeutic effect. Therefore our studies may help to develop a safe and effective vaccine against cervical 
cancer and other neoplasias associated with HPV infection in humans.

Acknowledgements This work was supported by a grant from The 863 High-Tech Projects of the Chinese Government (No. 2002AA216041).

\section{REFERENCES}

1) Zur Hausan H., Biochem. Biophys. Acta, 1288, 55-78 (1996).

2) Walboomers J. M., Jacobs M. V., Manos M. M., Bosch F. X., Kumme J. A., Shah K. V., Snijdesr P. F., Peto J., Meijer C. L. M., Muňoz C. L. M., J. Pathol., 189, 12-19 (1999).

3) Crook T., Morgenstern J. P., Crawford L., Banks L., EMBO J., 8, 513-519 (1989)

4) Schwartz E., Freese V. K., Gissman L., Nature (London), 314, 111 114 (1985).

5) Chen L. P., Thomas E. K., Hu S. L., Haltom I., Hellstrom K. E., Proc. Natl. Acad. Sci. U.S.A., 88, 110-114 (1991).

6) Benton C., Shahidullah H., Hunter J. A. A., Papillomavirus Rep., 1 $323-326$ (1992)

7) Aiba S., Rokugo M., Tagami H., Cancer, 58, 1246-1251 (1986).

8) Kadish A. S., Ho G. Y. F., Burk R. D., Wang Y., Romney S. L., Ledwidge R., Angeletti R. H., Cancer Res., 89, 1285-1293 (1997).

9) Evans E. M.-L., Man S., Evans A. S., Borysiewicz L. K., Cancer Res., 57, 2943-2950 (1997).

10) Daemen T., Rents J., Holtrop M., Wilschut J., Gene Therapy, 9, 8594 (2002).

11) He Z., Wlazlo A. P., Kowalczyk D. W., Cheng J., Xiang Z. Q., GilesDavis W., Ertl H. C. J., Virology, 48, 6-29 (2000).

12) Fernamdo G. J. P., Murray B., Zhou J., Frazer I. H., Clin. Exp. Immunol., 115, 397-403 (1999).

13) De Bruijn M. L. H., Schuurhuis D. H., Vierboom M. P. M., Vermeulen H., de Cock K. A. J., Omas M. D., Ressing M. E., Toebes M., Franken K. L. M. C., Drijfhout J.-W., Ottenhoff T. H. M., Offringa R., Melief C. J. M., Cancer Res., 58, 724-731 (1998).

14) Feltkamr M. C. W., Smits H. L., Vierboom M. P. M, Minaar R. P., Jongh B. M., Drijfhout M. J. W., Ter Schegget J., Melief C. J. M., Kast W. M., Europ. J. Immunol., 23, 2242-2249 (1993).

15) Feltkamr M. C. W., Vreugdenhil G. R., Vierboom M. P. M., Ras E., Van Der Burg S. H., Schegget J. T., Melief C. J. M., Kast W. M., Eur. J. Immunol., 25, 2638-2642 (1995).

16) Zhu X., Tommasinos M., Vousden K., Sadovnika D., Rappuoli R.
Crawford I., Kast W., Melief C. J. M., Beverley P. C. L, Stauss H. J., Scand. J. Immunol., 42, 557-563 (1995).

17) Gao L., Chain B., Sinclair C., Crawford L., Zhou J., Morris J., Zhu X., Stauss H., J. Gen. Virol., 75, 157-164 (1994).

18) Chu N. R., Wu H. B., Wu T.-C., Boux L. J., Siegel M. I., Mizzen A., Clin. Exp. Immunol., 121, 216-225 (2000).

19) Lin K.-Y., Guarnieri F. G., Staveley-O'Carroll K. F., Levitsky H. I., August J. T., Pardoll D. M., Wu T.-C., Cancer Res., 56, $21-26$ (1996).

20) Ji H. X., Chang E. Y., Lin K.-Y., Kurman R. J., Pardoll D. M., Wu T.C., Int. J. Cancer, 78, 41-45 (1998).

21) Thornburg C., Boczkowski D., Gilboa E., Nair S. K., J. Immunother. 23, 412-418 (2000).

22) Schäfer K., Müller M., Faath S., Henn A., Osen W., Zetgraf H., Benner A., Gissmann L., Jochmus I., Int. J. Cancer, 81, 881-888 (1999).

23) Resing M. E., Sette A., Bradt R. M. P., Ruppert J., Wenjtworth P. A., J. Immunol., 154, 5934-5943 (1995).

24) Van der Hulst J. M., Kwappenberg K. M. C., Hassane S., Franken K. L. M. C., Drijout J. W., Flenren G. J., Kenter D., Mtlief C. J. M., Offringa R., Van der Banderburg S. H., Cancer Res., 63, 636-641 (2003).

25) Murakami M., Gurski K. J., Marincola F. M., Ackland J., Steller M. A., Cancer Res., 59, 1184-1189 (1999).

26) Šmahel M., Šima P., Ludviková V., Vonka V., Virology, 281, 231-238 (2001).

27) Shi W., Bu P., Liu J., Polack A., Fisher S., Qiao L., J. Virol., 73, 7877-7881 (1999).

28) Wu T.-C., Guarnieri F. G., Staveley-O’Carroll K. F., Viscidi R. P., Levitsky H. I., Hedrick L., Cho K. R., August T., Pardoll D. M., Proc. Natl. Acad. Sci. U.S.A., 92, 11671-11675 (1995).

29) Korzeniewske C., Callewaert D. M., J. Immunol. Methods, 64, 313320 (1983).

30) Decker T., Lohmann-Matthes M. L., J. Immunol. Methods, 115, 6169 (1988)

31) Ma Y. W., Zhou X. S., Zhao Q. Z., Li Y. C., Biol. Pharm. Bull., 26, $137-140$ (2003)

32) He Z., Wlazlo A. P., Kowalczyk D. W., Cheng J., Xiang Z. Q., GilesDavis W., Ertl H. C., Virology, 270, 146-161 (2000).

33) Sundaram P., Tigelaa R. E., Xiao W., Brandsma J. L., Vaccine, 16, 613-623 (1998)

34) Kadish A. S., Ho G. Y. F., Burk R. D., Wang Y., Romney S. L., Ledwidge R., Angeletti R. H., J. Natl. Cancer Inst., 89, 1285-1293 (1997).

35) Lipford G. B., Bauer S., Wagner H., Immunology, 84, 298-303 (1995). 